\title{
VOC Emissions from Spruce Strands and Hemp Shive: In Search for a Low Emission Raw Material for Bio-Based Construction Materials
}

\author{
Tereza Adamová *, Jaromír Hradecký and Marek Prajer (D) \\ Faculty of Forestry and Wood Sciences, Czech University of Life Sciences, Kamýcká 129, \\ 16500 Prague 6, Czech Republic; hradecky@fld.czu.cz (J.H.); marek.prajer@gmail.com (M.P.) \\ * Correspondence: adamovat@fld.czu.cz
}

Received: 22 May 2019; Accepted: 19 June 2019; Published: 24 June 2019

check for updates

\begin{abstract}
Volatile organic compounds (VOCs) reduce indoor air quality. They are associated with negative effects on human health and wellbeing. In terms of legislation requirements and consumer pressure, VOCs from engineered wood materials are reduced due to use of water based additives and adhesives in their formulation. Therefore, the main source of VOCs remains the raw material-the wood itself. Alternatives to wood strands, annual plant materials, are tested nowadays due to their advantages: The short cycle; the raw material is sourced naturally and can be produced more sustainably; and faster sequestering atmospheric carbon. The aim of this work was to investigate volatile organic compounds emitted from untreated and chemically treated hemp shive and compare the emission characteristics to soft wood strands. Simple, yet effective chemical treatments, like tartaric acid, citric acid and sodium bicarbonate were used in order to reduce VOC emissions. Gas chromatography-mass spectrometry (GC-MS) combined with headspace solid-phase microextraction (HS-SPME) was used to analyse the volatile compounds emissions. Specific VOCs like acetic acid; Benzaldehyde; hexanal, $\alpha$-, $\beta$-pinenes; limonene and camphene were monitored before and after the treatments. Non-target screening was performed to identify the most responsible compound for differentiation of samples according to their treatments. Comparing untreated samples, spruce strands showed highest amounts of total VOCs, while untreated hemp shive showed the lowest. Further, due to the chemical modification of hemp woody core components, such as hemicelluloses, lignin, and extractives, the key VOCs showed significant changes leading to an increase in the amount of total emissions.
\end{abstract}

Keywords: gas chromatography-mass spectrometry (GC-MS); headspace solid-phase microextraction (HS-SPME); chemical treatment; volatile organic compounds (VOCs)

\section{Introduction}

Due to a large amount of building materials based on engineered wood, it is nowadays increasingly used in building constructions and their exposure to indoor air, volatile organic compounds (VOCs) released from wood based materials is recognized as one of the factors to influence indoor air quality $[1,2]$. As people in the 21st century spend a considerable part of their life-time indoors, in certain conditions, they are predisposed to the sick building syndrome [3]. In that case, inhabitants of poorly ventilated buildings are more prone to suffer from various symptoms like headaches as: Eye, nose or throat irritations; dry coughs; allergy reactions; dry and itching skin; nonspecific hypersensitivity; insomnia; dizziness and nausea or difficulty in concentrating; and tiredness. The intense odors may have a negative psychological influence as well [4]. Increasing concerns of human wellbeing are strictly connected to indoor environmental quality. The selection of building materials plays a key role in its 
occupants wellbeing, thus there is a demand for a reduction of VOCs, even in eco-materials used in today's architecture and structural application $[5,6]$.

The wooden indoor environment is beneficial to its occupants who suffer less tension and fatigue as VOCs emitted from wood actually can have a positive effect on human health. Wood based panels and materials are often composed of wooden fibers, particles, strands or veneers bonded with several chemical compounds and additives $[7,8]$. Less harmful chemicals are being used due to environmental and health concerns, and the emissions of VOCs from manufacturing-aid additives, glues, coatings and polymers are being steadily reduced [9]. Furthermore, the possibilities to reduce VOCs released from the natural component of panels, wood, still remains. Attempts to reduce VOCs from wood based materials and structures were made by: Applying coatings containing dispersed nanoparticles with high surface to volume ratio [10]; thermal treatment [11]; manufacturing process modifications [12]; or using buffering capacity of other structural components [13]; or even adding scavengers, such as pozzolan, directly into the medium-density fibreboard (MDF) formulation [14].

Naturally, the type and amount of VOCs released from wood or other plant material depend on the plant type, life history, interaction with biotic and abiotic factors, diseases, soil quality, nutrition, irrigation, weather and climate conditions, health of the plant, as well as its life cycle period (e.g., hibernation) at the moment of timber material production $[15,16]$. Apart from cellulose, hemicelluloses and lignin, wood and other botanical fibers are composed of low molecular weight organic chemicals, extractives [17]. Their content varies from 0.5 to 20 weight (wt.) \% in wood [18] and from 1 to $3 \mathrm{wt} . \%$ in natural fibers [15]. Provided that degradation of lignin and celluloses during the molding process of wood based structural components is minimized, extractives can be considered as a primary source of VOC emissions [19]. Combining benefits of a fast and straightforward production with presumably low VOC emissions, short life cycle, low density and reasonably good mechanical properties, may set structural bio-based materials based on annual plant fibers as a promising alternative to commonly used engineered wood [20,21].

One such a plant is hemp (Cannabis sativa), a fast growing wood-like annual plant, native in Central Asia, close to stinging nettle and belonging to cannabinaceae family. Nowadays, it has been planted in many places around the northern hemisphere. Large amounts of the plant can be harvested at a relatively low cost $[22,23]$. Hemp shive is a woody core of the hemp stalk with outstanding thermal insulation properties. It is characterized by high porosity, low thermal conductivity and high thermal capacity. It has a microstructure similar to hardwoods with three major layers in the cell wall: Middle lamella, primary cell wall and secondary cell wall [24]. Due to its good physical, chemical and mechanical properties, it has been also used in manufacturing of bio-composites, lightweight and insulating concretes and insulation mats in the construction industry. It ensures better elasticity and higher bearing capacity than solid wood, thus it can easily replace the traditional oriented strand board (OSB)-gypsum-water/air barrier-insulation wall composition [22,25]. Hemp based materials are used either raw (shive or fiber, thermal insulation) or processed (together with glues, polymer matrices or other cohesion improving agents).

Hemp shive and silica sol based novel building composites were investigated using gas chromatography-mass spectrometry (GC-MS). The yield of total extractives reached $6.23 \%$ (dry wt.\%) followed by low density and enhanced water resistance of a composite [26]. Hemp shive mixed with slaked lime (calcium hydroxide) provides a building material which is solid, durable, soundproof, mold resistant and highly usable bio-based insulation. To become a building and construction material, hemp shive requires minimum processing. Its use represents a more environmentally-friendly way comparing to traditional building materials based on iron or glass, leading to buildings' ecological balance improvement throughout their entire life cycle. Furthermore, lime-hemp materials contribute to $\mathrm{CO}_{2}$ emissions reduction. $\mathrm{CO}_{2}$ is absorbed while hemp is planted as well as during the process when slaked lime is curing into limestone (calcium carbonate) again $[22,27,28]$.

Since VOCs presence in indoor air is a case of concern (regarding sick building syndrome), confirmation of VOC emissions from building products is needed [16]. The aim of this study was to 
determine hemp shive (Cannabis sativa L.) VOC emissions before and after simple chemical treatments, and to compare VOC emissions intensity with spruce strands' (Picea abies).

\section{Materials and Methods}

\subsection{Chemicals}

Tartaric acid $\left(\mathrm{C}_{4} \mathrm{H}_{6} \mathrm{O}_{6}\right)$, citric acid-monohydrate $\left(\mathrm{C}_{6} \mathrm{H}_{8} \mathrm{O}_{7} \cdot \mathrm{H}_{2} \mathrm{O}\right)$ and sodium bicarbonate $\left(\mathrm{NaHCO}_{3}\right)$ were purchased from Lach-ner (Neratovice, Czech Republic). A crystalline form of all chemicals was further dissolved in distilled water (Millipore-Elix,-Simplicity) to prepare an aqueous solution of a specific concentration.

\subsection{Samples}

Spruce strands were sourced from an OSB producer. Prior to processing, raw spruce logs were stored outdoors on the producer's site, unbarked in the first step and split single-stage way in a disk mill into strands. Afterwards, the spruce strands were dried to 3\% moisture content. Spruce strands were sampled on the producer's site before admixing any adhesives. The size of spruce strands was modified to (3-10) $\times 2 \times 1 \mathrm{~mm}$ (length $\times$ width $\times$ thickness) in the wood processing laboratory, Faculty of Forestry and Wood Sciences-Prague. Hemp shive was purchased from a local supplier of sustainable building materials. It was an industrial hemp grown in the UK and processed exclusively for Lhoist UK that uses it for construction purposes. During hemp processing, fiber and other parts of the plant were removed, where the hemp shive was ready to be used for building purposes. The size of individual shive particles varied among $(4-10) \times(2-5) \times 3 \mathrm{~mm}$. Two months prior to the start of experiment, all samples were stored in the laboratory in containers with a low amount of headspace.

\subsection{Chemical Treatment}

Citric acid and tartaric acid, acidic aqueous solutions, previously used by Wilke et al. [29] to reduce VOC emissions from wood-based construction materials, and alkalic sodium bicarbonate [30] aqueous solution were used to modify the hemp shive in order to further reduce its VOC emissions. Low chemical concentrations applied at room temperature were chosen in order not to compromise mechanical properties of the shive. Citric acid, tartaric acid and sodium bicarbonate were dissolved to get $6 \%$ (Table 1) in $0.5 \mathrm{~L}$ glass beakers, dry hemp shives were added and pressed under the liquid surface using another, smaller beaker. After $24 \mathrm{~h}$ of treatment, treated hemp shives were dried in a circulating air oven at $40{ }^{\circ} \mathrm{C}$ overnight to a constant water content $(10 \mathrm{wt} . \%)$ and placed into open headspace vials (each containing a $0.5 \mathrm{~g}$ of a sample)-Figure 1 . Spruce strands, as well as part of hemp shives, were dried and placed into vials without any chemical pre-treatment-in this study spruce strands served only as a reference. The samples placed in open vials were stored in closed glass desiccators (volume of $24 \mathrm{~L}$ ) connected to a supply of dry and purified air with a constant flow of $0.5 \mathrm{~L} \cdot \mathrm{min}^{-1}$ at $23^{\circ} \mathrm{C}$. This approach allowed a controlled air exchange while observing material degradation and volatile emissions [29].

Table 1. Spruce strands and hemp shive modifications ( $\mathrm{S}$ - spruce strands, $\mathrm{H}$ - untreated hemp shive, $\mathrm{H}_{\mathrm{A}}$ - hemp shive after tartaric acid treatment, $\mathrm{H}_{\mathrm{B}}$ - hemp shive after citric acid treatment, $\mathrm{H}_{\mathrm{C}}$ - hemp shive after sodium bicarbonate treatment).

\begin{tabular}{ccccccc}
\hline \multirow{2}{*}{ SAMPLE/Designation } & \multicolumn{6}{c}{ Spruce Hemp } \\
\cline { 2 - 6 } & $\mathbf{S}$ & $\mathbf{H}$ & \multicolumn{1}{c}{$\mathbf{H}_{\mathbf{A}}$} & \multicolumn{1}{c}{$\mathbf{H}_{\mathbf{B}}$} & \multicolumn{1}{c}{$\mathbf{H}_{\mathbf{C}}$} \\
\hline Treatment & - & - & Tartaric acid & Citric acid & Sodium bicarbonate \\
Solution concentration (wt.\%) & - & - & 6 & 6 & 6 \\
Soaking time (h) & - & - & 24 & 24 & 24 \\
\hline
\end{tabular}

Note: all samples were dried up to $10 \%$ moisture content prior inserted into vials. 


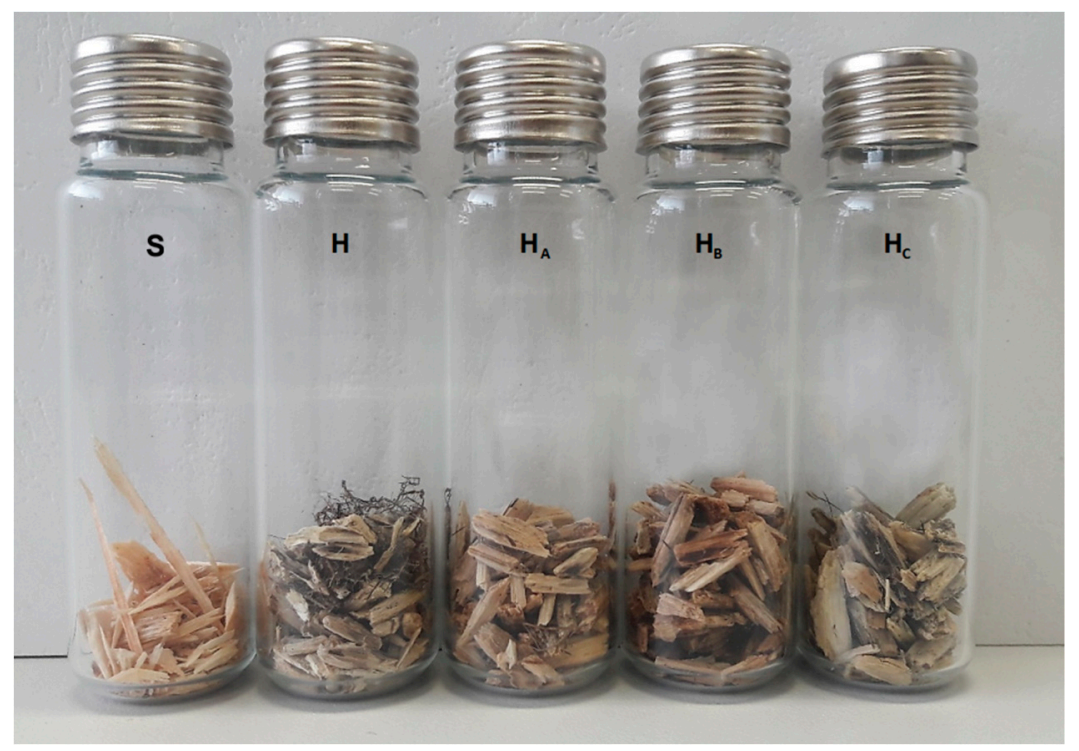

Figure 1. The samples closed in vials ready for GC-MS analysis-visual color change: (S-spruce strands, $\mathrm{H}$ - untreated hemp shive, $\mathrm{H}_{\mathrm{A}}$ - hemp shive after tartaric acid treatment, $\mathrm{H}_{\mathrm{B}}$ - hemp shive after citric acid treatment, $\mathrm{H}_{\mathrm{C}}$ - hemp shive after sodium bicarbonate treatment).

\subsection{Extraction of Volatiles, GC-MS Analysis and Data Processing}

The samples of un/treated hemp shives and spruce strands were placed separately in desiccators and analyzed for their volatile content after days 1, 3, 7 and 14 using GC-MS. To avoid instrumental sensitivity changes, samples were measured in one sequence. Before analysis, samples were stored airtight closed in vials in deepfreeze $\left(-80^{\circ} \mathrm{C}\right)$. For volatile organic compound collection, solid-phase microextraction, fibers with a divinylbenzen/carboxen/polydimethylsiloxan (DVB/CAR/PDMS 50/30 $\mu \mathrm{m}$ ) coating from Supelco (Bellefonte, PA, USA) was employed. Vials were incubated for $10 \mathrm{~min}$ to increase volatiles emission from the sample and then, volatiles were collected onto a fibers' stationary phase for the next $10 \mathrm{~min}$, both at $100^{\circ} \mathrm{C}$.

Gas chromatography coupled to mass spectrometry (GC-MS) was applied for VOCs separation and identification. Basic measurements were performed using Quadrupole Shimadzu GC-MS QP2010 SE-Ultra, applying SLB-5MS capillary column $(30 \mathrm{~m}, 0.25 \mathrm{~mm}$ i.d., $0.25 \mu \mathrm{m}$ film thickness) from Supelco. The injection was performed at $250{ }^{\circ} \mathrm{C}$, while the transfer line was kept at $280{ }^{\circ} \mathrm{C}$. The temperature program was as follows: $40^{\circ} \mathrm{C}$ for $1 \mathrm{~min}$ and then with grad $5{ }^{\circ} \mathrm{C} \mathrm{min}-1$ to $250{ }^{\circ} \mathrm{C}$ and held for $2 \mathrm{~min}$. Total run time was $45 \mathrm{~min}$. Helium was used as a carrier gas at a flow rate of $1 \mathrm{~mL} \cdot \mathrm{min}^{-1}$.

A group of target compounds was based on the literature. Nevertheless, in order not to focus only on few selected compounds, a mass analyzer was operated in SCAN mode (scan speed $2000 \mathrm{~ns}$, range 30-400 m/z). The identification of chemical compounds was based on mass spectral similarity with the in-built NIST MS library (NIST, Gaithersburg, MD, USA; 2017 released version). For confirmation of target compounds identity, retention times of respective standards (Sigma-Aldrich; Germany) were used.

Consequently, GC-MS with time of flight (TOF) mass analyzer Pegasus 4D (LECO, St. Joseph, MI, USA) was used to analyze an identical sample set. The aim was to obtain full spectral data for future chemometric evaluation. The sampling procedure remained the same, while for GC separation faster ramping was used. The GC oven temperature program was as follows: $40^{\circ} \mathrm{C}$ for $1 \mathrm{~min}$; then ramped at a rate of $10{ }^{\circ} \mathrm{C} \mathrm{min}-1$ to $70{ }^{\circ} \mathrm{C}$; then at $5{ }^{\circ} \mathrm{C} \mathrm{min}^{-1}$ to $200{ }^{\circ} \mathrm{C}$ and at $20{ }^{\circ} \mathrm{C} \mathrm{min}-1$ to $28{ }^{\circ} \mathrm{C}$ and held for $1 \mathrm{~min}$. The total GC run time was $21 \mathrm{~min}$.

Automated spectral deconvolution and peak finding algorithms were carried out using ChromaTOF software (LECO, St. Joseph, MI, USA). A build in peak alignment tool, Statistical Compare, was used to align all chromatographic signals with a signal to noise ratio $(\mathrm{S} / \mathrm{N})$ higher 
than 50 in all samples. The data measured using the TOF mass spectrometer were normalized (constant raw sum) and then evaluated using principal component analysis (PCA) and partial least square-discriminant analysis (PLS-DA) in SIMCA 15 software (Sartorius Stedim Data Analytics AB, Malmö, Sweden).

The reported intensities are areas of a unique mass-the specific mass of the compounds' mass spectrum - that does not co-elute with another compounds signal at a signal's retention time. For reported compounds RSD (relative standard deviation, expressed as \%) from 7 individual measurements was checked and was below $20 \%$.

\section{Results and Discussion}

In this work, hemp shives were subjected to simple chemical treatments, and their VOCs were analyzed and compared to untreated hemp shives and spruce strands. Thirteen key volatile organic compounds including carbonyl compounds, alkanes, aromatic hydrocarbons and terpenes were collected from untreated and chemically treated hemp shives by HS-SPME GC-MS. Target compounds (Table 2) were selected based on a list published in ISO 16000-6 (Annex A) dealing with the building products' VOC emissions in indoor air [31].

In general, a higher number of VOCs, as well as higher detector responses, were observed in spruce strands compared to untreated hemp (Figure 2), especially in case of Pentanal, Hexanal, Furfural and Benzaldehyde. This observation corresponds with an expected higher content of extractives in spruce wood [14,17].

Small test chambers were used to simulate typical interior room conditions where partial changes of air volume were taking place continuously [15]. After 14 days of storage in desiccators with a constant air flow, a slight decrease in intensity signal of above mentioned compounds was observed. A pentanal increase was reported only after sodium bicarbonate treatment and it was later decreasing during storage. Together with more important aldehyde-hexanal, it is known as a product of unsaturated fatty acids oxidation [14]. Both compounds have been identified as causing unpleasant, irritating odors [32] and are known to cause off-flavors in low concentrations in paper [33]. Hexanal, described as grassy [34], kept its initial value after sodium bicarbonate treatment. It was then increasing in all other materials (Figure 3) during storage (especially in case of untreated hemp).

Both materials in untreated forms emitted similar amounts of acetic acid. Meanwhile acidic treatments enhanced the emission of this compound; sodium bicarbonate treatment led to its inhibition. Unpleasantly smelling butanoic acid was not present in untreated hemp as well as in sodium bicarbonate treated samples (signal below limit of detection-LOD), while the acid treatment significantly increased its abundance. Comparing the untreated and sodium bicarbonate treated hemp shive, aldehyde (hexanal and octanal) emissions lowering effect of sodium bicarbonate was observed, while the emission of other compounds (especially terpenes) rose. 
Table 2. The intensities of monitored VOC emissions; intensities detector response for unique mass: (S—spruce strands, $\mathrm{H}-\mathrm{untreated}$ hemp shive, $\mathrm{H}_{\mathrm{A}}-$ hemp shive after tartaric acid treatment, $\mathrm{H}_{\mathrm{B}}$ - hemp shive after citric acid treatment, $\mathrm{H}_{\mathrm{C}}$ - hemp shive after sodium bicarbonate treatment).

\begin{tabular}{|c|c|c|c|c|c|c|c|c|c|c|c|c|c|c|c|c|c|c|c|c|}
\hline \multirow{3}{*}{ COMPOUND } & \multicolumn{20}{|c|}{ SAMPLES \& SAMPLING DAYS } \\
\hline & \multicolumn{4}{|c|}{$\mathrm{S}$} & \multicolumn{4}{|c|}{$\mathbf{H}$} & \multicolumn{4}{|c|}{$\mathbf{H}_{\mathbf{A}}$} & \multicolumn{4}{|c|}{$\mathbf{H}_{\mathbf{B}}$} & \multicolumn{4}{|c|}{$\mathbf{H}_{\mathbf{C}}$} \\
\hline & 1 & 3 & 7 & 14 & 1 & 3 & 7 & 14 & 1 & 3 & 7 & 14 & 1 & 3 & 7 & 14 & 1 & 3 & 7 & 14 \\
\hline Acetic acid & 20 & 12 & 12 & 1 & 23 & 90 & 2 & 2 & 90 & 62 & 38 & 38 & 177 & 68 & 44 & 35 & 6 & 6 & 3 & 1 \\
\hline Butanoic acid & 105 & 98 & 103 & 113 & / & / & l & / & 20 & 20 & 22 & 26 & 22 & 23 & 25 & 26 & / & / & l & / \\
\hline Hexanal & 805 & 669 & 668 & 925 & 273 & 320 & 372 & 704 & 606 & 582 & 650 & 798 & 577 & 554 & 607 & 787 & 379 & 356 & 408 & 375 \\
\hline Furfural & 315 & 520 & 342 & 394 & 12 & 19 & 12 & 16 & 10638 & 9191 & 5609 & 6672 & 8427 & 5639 & 2557 & 2419 & 92 & 86 & 59 & 61 \\
\hline alpha-Pinene & 1377 & 7345 & 2815 & 4872 & 666 & 285 & 244 & 24 & 697 & 729 & 594 & 279 & 679 & 572 & 639 & 253 & 887 & 782 & 883 & 303 \\
\hline Camphene & 120 & 145 & 63 & 113 & 190 & 83 & 68 & 3 & 224 & 233 & 181 & 89 & 247 & 192 & 202 & 82 & 265 & 236 & 259 & 87 \\
\hline Benzaldehyde & 821 & 1360 & 897 & 1619 & 379 & 274 & 287 & 381 & 791 & 676 & 560 & 467 & 697 & 704 & 558 & 540 & 952 & 873 & 682 & 579 \\
\hline beta-Pinene & 761 & 1066 & 271 & 2189 & 441 & 197 & 172 & / & 409 & 440 & 391 & 196 & 291 & 286 & 385 & 177 & 649 & 612 & 646 & 233 \\
\hline 3-Octanone & 1 & l & 1 & 3 & / & 2 & 2 & 1 & 1 & l & l & 2 & 3 & l & l & l & 4 & 4 & 3 & 2 \\
\hline beta-Myrcene & 176 & 212 & 88 & 147 & 381 & 149 & 142 & 7 & 388 & 365 & 312 & 148 & 382 & 293 & 345 & 141 & 525 & 491 & 501 & 164 \\
\hline Octanal & 98 & 100 & 100 & 116 & 36 & 31 & 46 & 65 & 92 & 87 & 81 & 90 & 71 & 76 & 80 & 82 & 41 & 456 & 44 & 51 \\
\hline Limonene & 818 & 896 & 503 & 147 & 475 & 191 & 190 & 89 & 490 & 500 & 500 & 203 & 585 & 426 & 459 & 194 & 602 & 605 & 593 & 214 \\
\hline
\end{tabular}




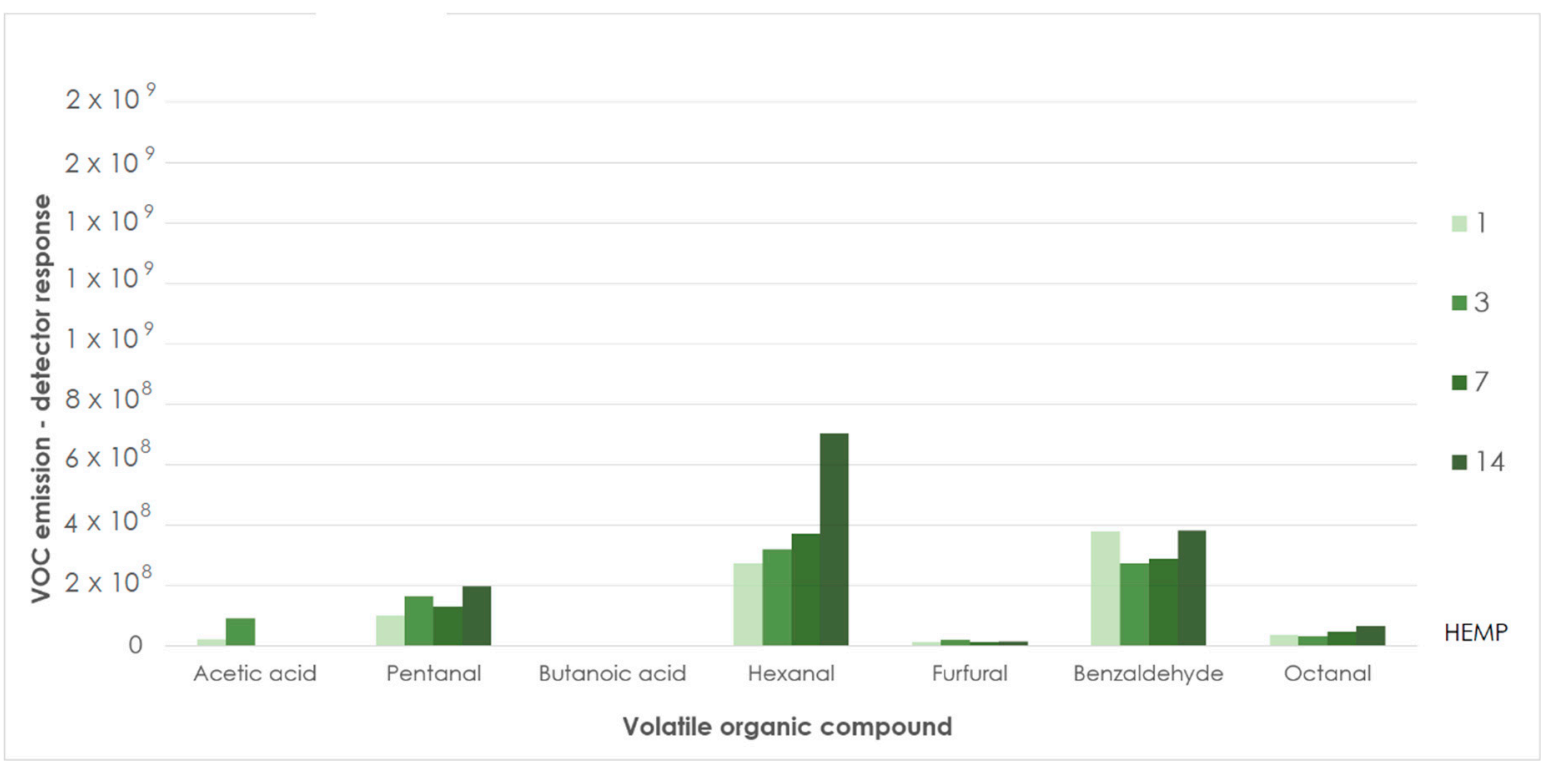

(a)

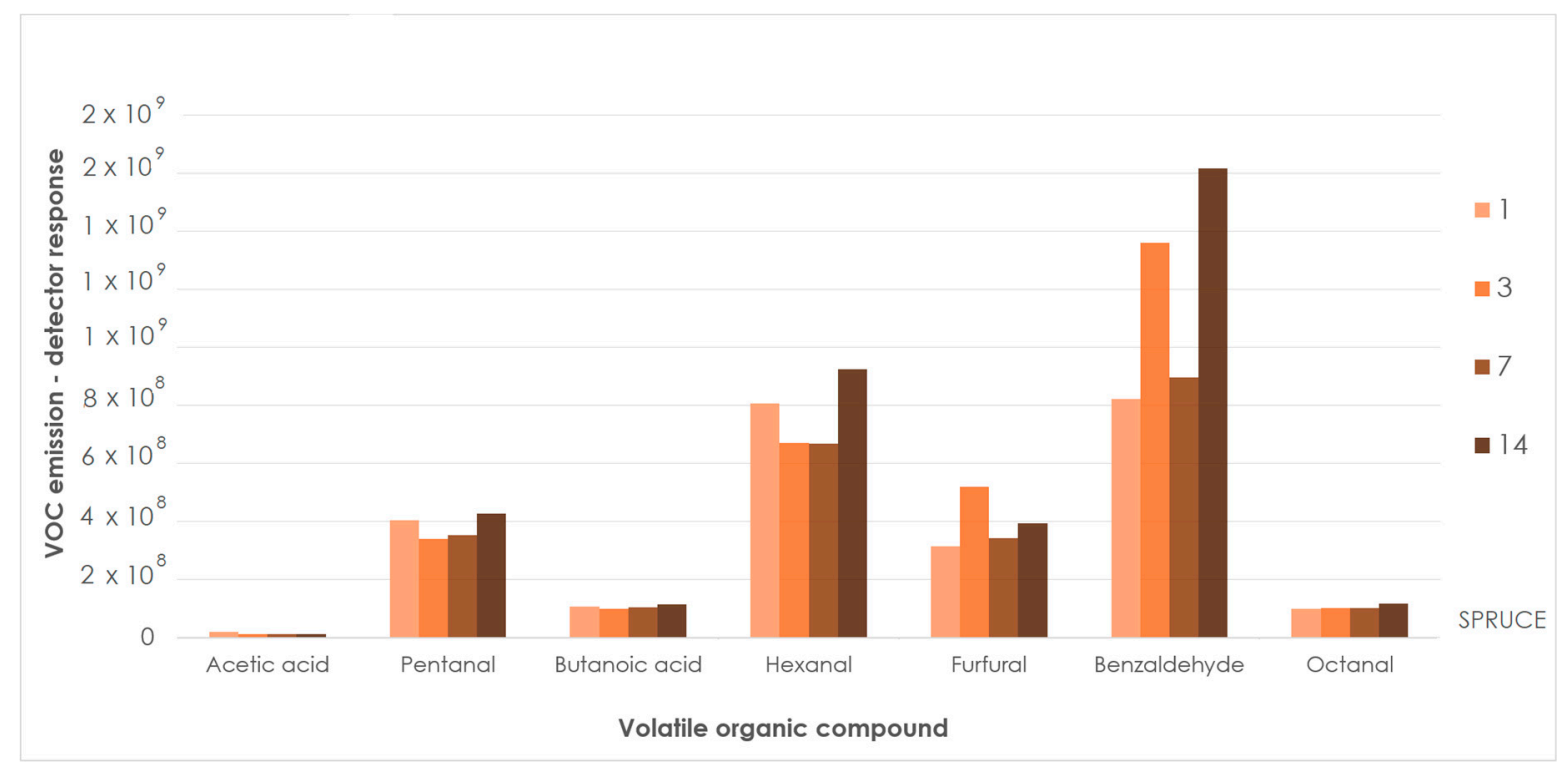

(b)

Figure 2. Selected VOC emissions from spruce wood and untreated hemp (day 1, 3, 7, 14; detector response for unique mass) (a): untreated hemp shive; (b): spruce strands.

A wide variety of terpenes (such as alpha-pinene, beta-pinene, camphene, 3-carene and limonene) was observed (Figure 4) in both samples (spruce and hemp). Nevertheless, it should be noted that even higher responses of terpenes in the case of hemp were still significantly lower than those measured in the spruce samples. Moreover the amount was decreasing with time.

Basic chemometric data evaluation using PCA clearly demonstrated the separation of spruce strands samples from all hemp samples. It was caused by higher relative abundance of characteristic spruce wood volatiles, alpha and beta-pinene. These findings confirmed a difference in released VOCs between untreated spruce strands and untreated hemp shives, showing that untreated hemp shives can be regarded as a safe construction material for indoor air quality. 
To further investigate differences among hemp treatments, partial least square-discriminant analysis (PLS-DA) was performed. No separation was observed according to the duration of storage, while samples were separated based on chemical solutions treatment (Figure 5).

In the case of hemp, both acid treated samples formed one group, mainly due to higher abundance of furfural (Figure 6). Furfural may be formed under thermal stress from degradation of polyoses (hemicellulose) [35]. It is often used for industrial manufacturing, food flavoring, for fragrance in personal care products or as a book papers preservative. This compound is considered to be relatively harmless [36]. The samples of sodium bicarbonate treated hemp shive separated due to higher relative abundance of pentanal and 2-methyl-3-butene-2-ol being used as a fragrance ingredient in cosmetics, fine fragrances, shampoos, toilet soaps and other toiletries as well as in non-cosmetic products, such as household cleaners and detergents [37].

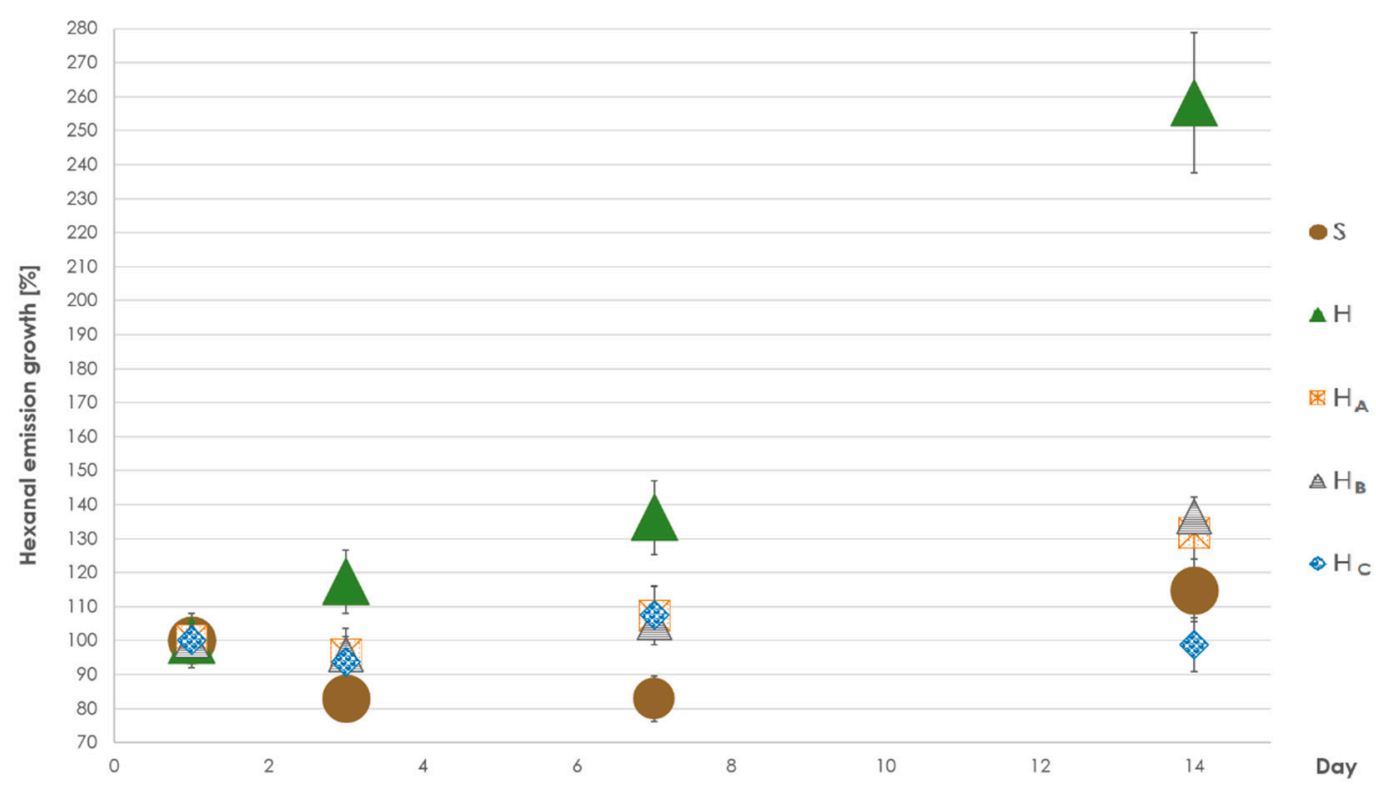

Figure 3. Hexanal emission changes (in \%) in tested materials after storage in desiccators (day 1, 3, 7, 14); unique mass intensities first sampling day were considered as $100 \%$. Error bars represent twice relative standard deviation of hexanal intensity measurement in 7 tested samples (8\%). (S-spruce strands, $\mathrm{H}$ - untreated hemp shive, $\mathrm{H}_{\mathrm{A}}$ - hemp shive after tartaric acid treatment, $\mathrm{H}_{\mathrm{B}}$ - hemp shive after citric acid treatment, $\mathrm{H}_{\mathrm{C}}$ - hemp shive after sodium bicarbonate treatment).

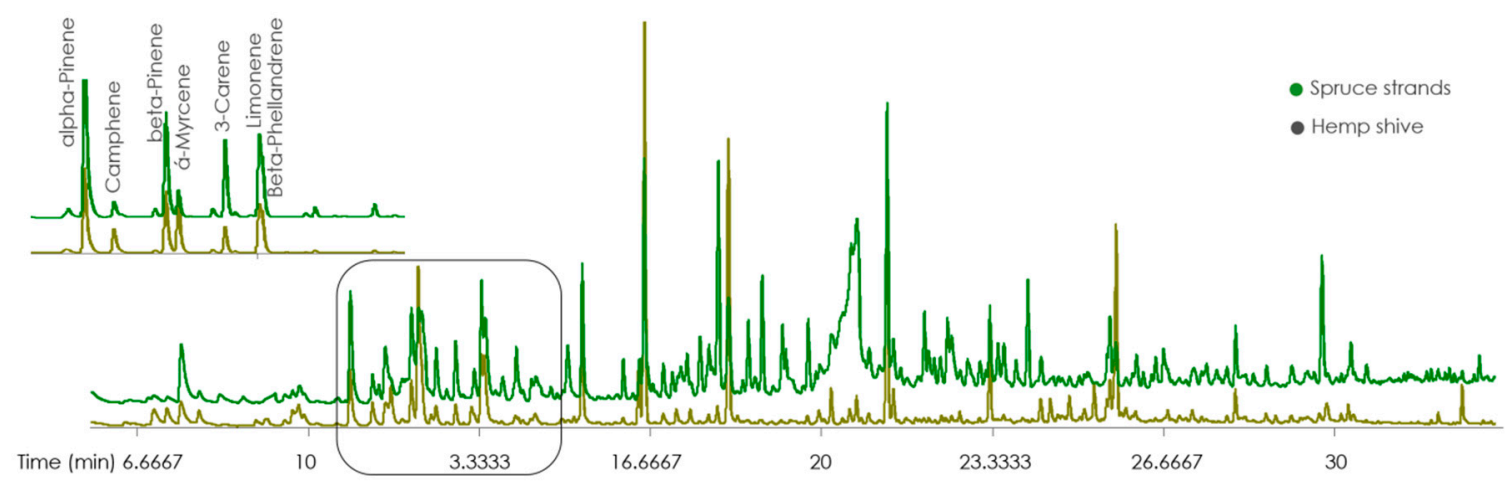

Figure 4. Chromatograms of VOCs extracted from spruce strands and hemp shives (with a focus on terpenes). 


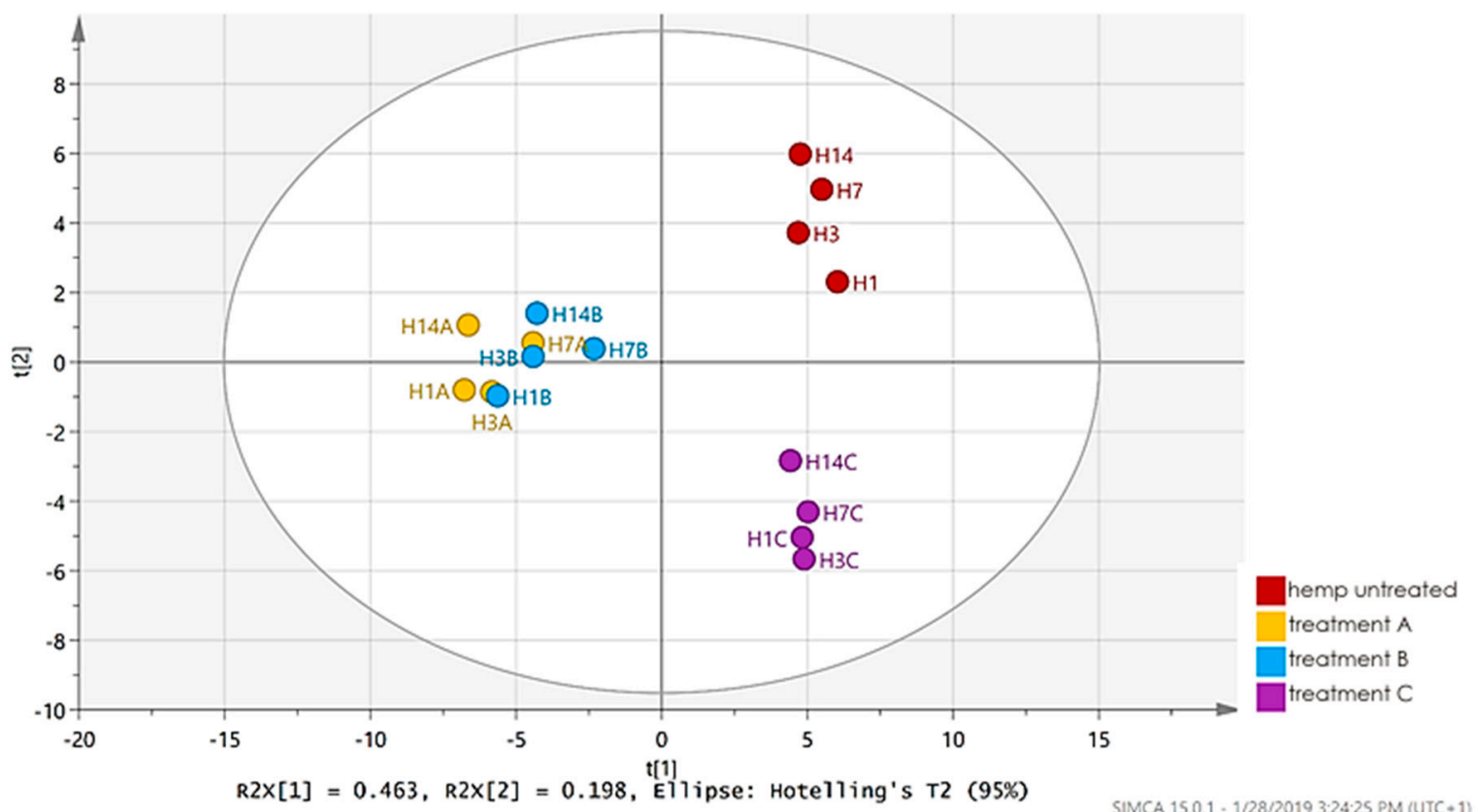

Figure 5. PLS-DA score plot: (H1-14-hemp with no treatment, H1A-14A-hemp shive and tartaric acid; H1B-14B — hemp shive and citric acid; H1C-14C—-hemp shive and sodium bicarbonate)

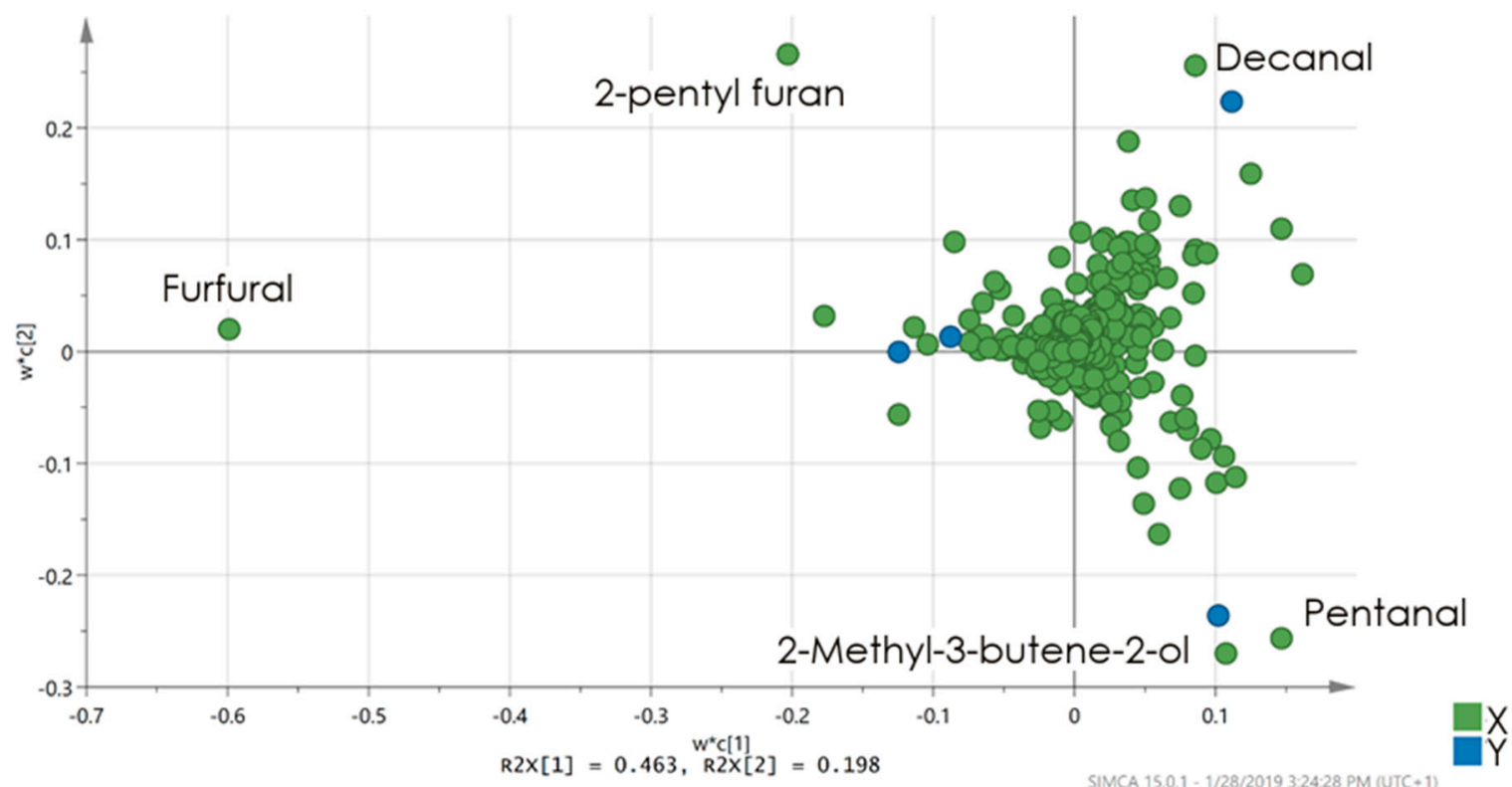

Figure 6. PLS-DA loadings plot presenting significant markers for each treatment. Compounds identification was based on mass spectral similarity and retention index comparison. The identified compounds (pentanal, furfural, 2-pentyl furan, decanal, 2-methyl-3-butene-2-ol) importance is correlating with a distance from the central point; the further the distance, the higher is the markers importance.

Simple chemical treatments did not further decrease VOC emissions from hemp shives. Nevertheless, the amount of released VOCs compounds was still lower compared to untreated spruce strands.

The chemical composition of raw material used for building materials production represents only one of the factors affecting the quality of indoor air. In addition, the performance of building materials and therefore VOCs release, depends on prevailing thermal and moisture conditions, air pressure difference over the structure, structural design and the quality of construction work, volume 
of air contained in the indoor space, rate of production or release of the pollutant, the rate of removal of the pollutant from the air via reaction or settling, and the rate of air exchange with the outside atmosphere [20]. The impact of these factors on VOCs release was not considered in presented study.

\section{Conclusions}

Natural fibers can be used as an alternative to wood in advanced composite applications, in terms of their mechanical properties. To assist in the prediction of the final product influence on indoor air quality, raw solids used for boards processing should be tested to provide information on VOC emissions. Considering raw untreated samples, hemp shive showed a significantly lower amount of total VOCs comparing to spruce. The present analysis did not prove a simple chemical pre-treatment can reduce the overall VOC emissions from hemp. Due to chemical modification of hemp woody core components, such as hemicelluloses, lignin and extractives, the key VOCs showed significant changes, leading to an increase in the amount of total emissions. Nevertheless, particular emissions can be reduced or kept at initial values. In conclusion, material from annual plants like hemp shive proved to be a viable alternative to spruce strands for bio-based materials in terms of VOCs reduction.

Author Contributions: The work presented in this paper is a collaborative development by all of the authors. Conceptualization, M.P.; Data curation, T.A.; Investigation, T.A.; Methodology, J.H. and M.P.; Validation, J.H.; Visualization, T.A.; Writing—original draft, T.A.; Writing—review \& editing, J.H. and M.P.

Funding: This work was supported by grant "EVA 4.0", No. CZ.02.1.01/0.0/0.0/16_019/0000803 financed by OP RDE.

Conflicts of Interest: The authors declare no conflict of interest.

\section{References}

1. Matsubara, E.; Kawai, S. VOCs emitted from Japanese cedar (Cryptomeria japonica) interior walls induce physiological relaxation. Build. Environ. 2014, 72, 125-130. [CrossRef]

2. An, J.-Y.; Kim, S.; Kim, H.-J. Formaldehyde and TVOCs emission behaviour of laminate flooring by structure of laminate flooring and heating condition. J. Hazard. Mater. 2011, 187, 44-51. [CrossRef] [PubMed]

3. Tanaka-Kagawa, T.; Uchiyama, S.; Matsushima, E.; Sasaki, A.; Kobayashi, H.; Kobayashi, H.; Yagi, M.; Tsuno, M.; Arao, M.; Ikemoto, K.; et al. Survey of volatile organic compounds found in indoor and outdoor air samples from Japan. Bull. Natl. Inst. Health Sci. 2005, 123, 27-31.

4. Maskell, D.; da Silva, C.F.; Mower, K.; Cheta, R.; Dengel, A.; Ball, R.; Ansell, M.; Walker, P.; Shea, A. Properties of bio-based insulation materials and their potential impact on indoor air quality. In Proceedings of the First International Conference on Bio-Based Building Materials, Clermont-Ferrand, France, 22-24 June 2015.

5. Skov, H.; Hansen, A.B.; Lorenzen, G.; Andersen, H.V.; Lofstrom, P.; Christensen, C.S. Benzene exposure and the effect of traffic pollution in Copenhagen Denmark. Atmos. Environ. 2001, 35, 2463-2471. [CrossRef]

6. Liu, Y.; Shen, J.; Zhu, X. Influence of processing parameters on VOC emission from particleboards. Environ. Monit. Assess. 2010, 171, 249-254. [CrossRef]

7. Xi, Z.; Zhiwei, L.; Wu, Y. Human physiological responses to wooden indoor environment. Physiol. Behav. 2017, 174, 27-34.

8. Irle, M.; Barbu, M.C. Wood-Based Panel Technology. In Wood-Based Panels: An Introduction for Specialists; Thoemen, H., Irle, M., Sernek, M., Eds.; Brunel University Press: London, UK, 2010; pp. 1-55. ISBN 978-1-902316-82-6.

9. Grand View Research; Low-Volatile Organic Compounds (VOC) Coating Additives Market Analysis, Market Size, Application Analysis, Regional Outlook, Competitive Strategies, and Forecasts, 2015-2022. Available online: https://www.grandviewresearch.com/industry-analysis/low-volatile-organic-compounds-coatingadditives-market (accessed on 1 February 2019).

10. Liu, Y.; Zhu, X. Measurement of formaldehyde and VOCs emissions from wood based panels with nanomaterial added melamine impregnated paper. Constr. Build. Mater. 2014, 66, 132-137. [CrossRef]

11. Huang, Y.; Zhang, Y.; Qi, Y.; Yu, Y.; Yu, W. Identification of odorous constituents of bamboo during thermal treatment. Constr. Build. Mater. 2019, 203, 104-110. [CrossRef] 
12. He, Z.; Zhang, Y.; Wei, W. Formaldehyde and VOC emissions at different manufacturing stages of wood based panels. Build. Environ. 2012, 47, 197-204. [CrossRef]

13. da Silva, C.F.; Cheta, R.; Maskell, R.; Dengel, A.; Ansell, M.P.; Ball, R. Influence of eco-materials on indoor air quality. Green Mater. 2016, 4, 72-80. [CrossRef]

14. Sumin, K. The reduction of indoor air pollutant from wood-based composite by adding pozzolan for building materials. Constr. Build. Mater. 2009, 23, 2319-2323. [CrossRef]

15. Stachowiak-Wencek, A.; Pradzyński, W. Emission of volatile organic compounds from wood of exotic species. For. Wood Technol. 2014, 86, 215-219.

16. Wolkoff, P. How to measure and evaluate volatile organic compound emissions from building products. A perspective. Sci. Total Environ. 1999, 227, 197-213. [CrossRef]

17. Chen, H. Biotechnology of Lignocellulose: Theory and Practice; Chemical Industry Press: Beijing, China, 2014; ISBN 978-94-007-6898-7.

18. Hill, C.A.S. Wood Modification: Chemical, Thermal and other Processes; Wiley-Blackwell: Chichester, UK, 2006; pp. 25-30. ISBN 0-470-02172-1.

19. Roffael, E. Significance of wood extractives for wood bonding. Appl. Microbiol. Biotechnol. 2016, 100, 1589-1596. [CrossRef] [PubMed]

20. Summerscales, J.; Dissanayake, N.; Hall, W.; Virk, A.S. A review of bast fibres and their composites. Part 1: Fibres as reinforcements. Compos. Part A Appl. Sci. Manuf. 2010, 41, 1329-1335. [CrossRef]

21. Koivula, M.; Kymäläinen, H.R.; Virta, J.; Hakkarainen, H.; Hussein, T.; Komulainen, J.; Koponen, H.; Hautala, M.; Hämeri, K.; Kanerva, P.; et al. Emissions from thermal insulations-Part 2: Evaluation of emissions from organic and inorganic insulations. Build. Environ. 2005, 40, 803-814. [CrossRef]

22. Çomak, B.; Bideci, A.; Bideci, Ö.S. Effects of hemp fibers on characteristics of cement based mortar. Constr. Build. Mater. 2018, 169, 794-799. [CrossRef]

23. Mwaikambo, L.Y.; Ansell, M.P. Chemical modification of hemp, sisal, jute, and kapok fibers by alkalization. J. Appl. Polym. Sci. 2002, 84, 2222-2234. [CrossRef]

24. Jiang, Y.; Lawrence, M.; Ansell, M.P.; Hussain, A. Cell wall microstructure, pore size distribution and absolute density of hemp shiv. R. Soc. Open Sci. 2018, 5, 171945. [CrossRef]

25. Donatelli, A.; Cuna, D.; Tagliente, M.A.; Protopapa, M.L.; Mevoli, A.; Aversa, P.; Blasi, C.; Capodieci, L.; Luprano, V.A.M. Effect of treatments on the aging behaviour of hemp fibres for building construction in the Mediterranean Area. J. Build. Eng. 2017, 11, 37-47. [CrossRef]

26. Hussain, A.; Calabria-Holley, J.; Lawrence, M.; Ansell, M.P.; Jiang, Y.; Schorr, D.; Blanchet, P. Development of novel building composites based on hemp and multi-functional silica matrix. Compos. Part B Eng. 2019, 156, 266-273. [CrossRef]

27. Brzyski, P.; Łagód, G. Physical and mechanical properties of composites based on hemp shiv and lime. In SOLINA 2018-VII Conference SOLINA Sustainable Development: Architecture-Building Construction-Environmental Engineering and Protection Innovative Energy-Efficient Technologies-Utilization of Renewable Energy Sources, Proceedings of the Meeting SOLINA 2018, Polanczyk, Poland, 19-23 June 2018; Lichołai, L., Dębska, B., Miąsik, P., Szyszka, J., Krasoń, J., Szlachta, A., Eds.; EDP Sciences: Les Ulis, France, 2018; Volume 49, p. 00010.

28. Brzyski, P.; Barnat-Hunek, D.; Suchorab, Z.; Łagód, G. Composite materials based on hemp and flax for low-energy buildings. Materials 2017, 10, 510. [CrossRef] [PubMed]

29. Wilke, O.; Brozowski, F.; Wiegner, K.; Brauer, F. Bestimmung der VOC-Emissionen aus Grobspanplatten (OSB-Platten) und ihre Bewertung nach dem AgBB-Schema. Umwelt und Mensch Informationsdienst 2013, 1, 5-11.

30. Fiore, V.; Scalici, T.; Nicoletti, F.; Vitale, G.; Prestipino, M.; Valenza, A. A new eco-friendly chemical treatment of natural fibres: Effect of sodium bicarbonate on properties of sisal fibre and its epoxy composites. Compos. Part B Eng. 2016, 85, 150-160. [CrossRef]

31. ISO 16000-6:2011. Indoor Air_Part 6: Determination of Volatile Organic Compounds in Indoor and Test Chambre Air by Active Sampling on Tenax TA ${ }^{\circledR}$ Sorbent, Thermal Desorption and Ga $\backslash$ S Chromatography Using MS or MS-FID; ISO/TC 146; Technical Committee: Geneva, Switzerland, 2011.

32. NIOSH Pocket Guide to Chemical Hazards, Appendix: Aldehydes and NIOSH 2018: Aliphatic Aldehydes. Available online: http://www.cdc.gov/niosh/npg/npgd0652.html (accessed on 10 February 2019). 
33. Risholm-Sundman, M.; Lundgren, M.; Vestin, E.; Herder, P. Emissions of acetic acid and other volatile organic compounds from different species of solid wood. Holz als Roh-und Werkstoff 1998, 56, 125-129. [CrossRef]

34. Ernstgård, L.; Iregren, A.; Sjögren, B.; Svedberg, U.; Johanson, G. Acute effects of exposure to hexanal vapors in humans. J. Occup. Environ. Med. 2006, 48, 573-580. [CrossRef] [PubMed]

35. Salthammer, T.; Fuhrmann, F. Release of acetic acid and furfural from cork products. Indoor Air 2000, 10, 133-134. [CrossRef]

36. Eseyin, A.E.; Steele, P.H. An overview of the applications of furfural and its derivatives. Int. J. Adv. Chem. 2015, 3, 42-47. [CrossRef]

37. Api, A.M.; Belsito, D.; Bhatia, S.; Bruze, M.; Calow, P.; Dagli, M.L.; Dekant, W.; Fryer, A.D.; Kromidas, L.; La Cava, S.; et al. RIFM fragrance ingredient safety assessment, 2-methyl-3-buten-2-ol, CAS Registry Number 115-18-4. Food Chem. Toxicol. 2015, 84, S50-S56. [CrossRef]

(C) 2019 by the authors. Licensee MDPI, Basel, Switzerland. This article is an open access article distributed under the terms and conditions of the Creative Commons Attribution (CC BY) license (http://creativecommons.org/licenses/by/4.0/). 